\title{
EDUCAÇÃO ALÉM DA ESCOLA: ACOLHIDA A OUTROS SABERES
}

\section{ELIANA PEREZ GONÇALVES DE MOURA}

elianagm@feevale.br

\author{
DINORA TEREZA ZUCCHETTI \\ dinora@feevale.br
}

Pesquisadoras e docentes do Mestrado em Inclusão Social e Acessibilidade da

Universidade Feevale - Novo Hamburgo (RS)

\begin{abstract}
RESUMO
Nossa inserção na temática da educação no campo social advém de pesquisas que se baseiam nos princípios teórico-metodológicos da etnografia. Neste texto ensaiamos, na forma de um estudo teórico, nosso posicionamento sobre as práticas de educação além da escola, ancorado em quatro eixos balizadores. São eles: a urgente superação do debate sobre suas diversas formas de nomeação; o olhar mais minucioso para a questão da intencionalidade presente (ou não) nas práticas de educação no campo social; uma concepção ampliada de educação, designando-a como uma prática social que é também um ato político; a possibilidade de instauraçãa de outras bases teóricas para uma prática de educação que se constitua, pela atitude de abertura e acolhimento, um corpo de saberes transdisciplinar.

PRÁTICA DE ENSINO - EDUCAÇÃO - TRANSDISCIPLINARIDADE - PAPÉIS SOCIAIS
\end{abstract}

\begin{abstract}
EDUCATION BEYOND THE SCHOOL: EMBRACED BY OTHER KNOWLEDGES. Our involvement with the theme of education in the social field comes from research that is based on the theoretical and methodological principles of ethnography. In this text, which is by way of a theoretical study, we tested our position on the practices of education beyond the school, anchored to four supporting pillars. They are: urgently overcoming the debate about their various forms of appointment; a more detailed look at the issue of intentionality that is present (or not) in educational practices within the social field; an expanded concept of education, designating it as a social practice that is also a political act; the possibility of introducing other theoretical bases for educational practice that, because of its attitude of openness and welcoming acceptance, constitutes a transdisciplinary body of knowledge.

EDUCATIONAL PRACTICE - EDUCATION - TRANSDISCIPLINARITY - SOCIAL ROLE
\end{abstract}

Este texto foi ensejado por pesquisas mais ampliadas como a Formação de Educadores em Espaços Socioeducativos, em 2005, e a Educação, Trabalho, em 2007, ambas apoiadas pelo Conselho Nacional de Desenvolviento Científico e Tecnológico - CNPq - e a pesquisa Experiências Sociais no Campo Educativo Ambiental: Discursos e Práticas, em 2007, esta sem financiamento externo. 


\section{O DEBATE SOBRE FORMAS DE NOMEAÇÃO}

Os termos utilizados para definir as práticas de educação no campo social são diversos: educação não formal, educação informal, atividade extraclasse e/ou apoio socioeducativo, estes últimos quando voltados especificamente a crianças e jovens. Trata-se de práticas bastante heterogêneas, constituindo experiências e atividades de educação realizadas no interior dos movimentos sociais, organizações governamentais e não governamentais que acolhem crianças, jovens, mulheres, moradores dos bairros de periferias das grandes cidades, entre outros, e que desenvolvem desde ações assistenciais de alívio à pobreza até práticas de militância, sociabilidade, formação para o trabalho. Nesse campo é possível localizar até mesmo experiências que muitas vezes legitimam o trabalho infantil em nome da formação do futuro trabalhador ou formam para atividades de baixíssima qualificação.

Nesta seção, trataremos de evidenciar o caráter educativo das práticas de educação no campo social para apresentar alguns argumentos que nos levam a nomeá-las simplesmente como educação não escolar, além de demonstrar aquilo que efetivamente possuem em comum: o dissenso sobre suas formas de nomeação.

Apoiadas em autores como Paulo Freire (1989), Humberto Maturana ( 1999), Violeta Núñez Pérez (2003), Maria da Gloria Gohn (2005), entre outros, afirmamos nossa compreensão de que a educação está para além dos muros da escola e, nessa perspectiva, ressaltamos nossa convicção de que a educação escolar traz consigo a sua complementaridade: a educação não escolar.

Tensionadas pelo atual contexto social e político, analisamos o sentido do "não formal", com base no significado do termo formal. Segundo o Dicionário Houaiss da língua portuguesa, a classificação formal (frm.) corresponde aos cultismos, nitidamente marcados como forma erudita. Além disso, em nove, das 19 acepções listadas no dicionário, define-se o termo formal como algo: I. que não deixa dúvidas; claro, explícito, preciso; 2. que é real, evidente; manifesto, irrefutável, categórico; 3. que diz respeito mais à aparência do que ao conteúdo; 4. solene, oficial, sério, protocolar; 5. adequado para ocasiões solenes; 6. que não é espontâneo; convencional, institucional; 7. que valoriza muito as regras, o ritual; cerimonioso, protocolar; 8. Derivação por extensão 
de sentido: solene, grave, sério; 9. feito em estabelecimento de ensino, cumprindo a sequência e os programas escolares ou acadêmicos.

Diante do exame dos sentidos do termo formal, fomos conduzidas a rejeitar, de imediato, uma compreensão mais apressada de que a adoção do termo "não formal" poderia justificar-se pela sua oposição à formalização da escola e suas legislações, que impõem a participação compulsória de segmentos da sociedade de acordo com faixas cronologicamente estabelecidas.

Em primeiro lugar porque considerando a emergência de legislações afirmativas que sugerem ações que resgatam e reafirmam os direitos sociais da cidadania, passamos a suspeitar que essas práticas socioeducativas embora, geralmente, ocorrendo fora dos muros escolares, também se configuram como formais na medida em que se tornaram convencionais, institucionais. Estatuto da Criança e do Adolescente - ECA -, por exemplo, no artigo 90 - Das Entidades de Atendimento -, não deixa dúvidas sobre a formalidade dessas práticas e dos programas de proteção sendo que, em alguns casos, faz-se presente a obrigatoriedade da intervenção do Estado, no caso de haver determinação judicial, configurando algo que não é da ordem do espontâneo, ao contrário, é solene, grave, sério.

Além disso, esse artigo do ECA reitera que as entidades de caráter social, educativas ou de qualquer outra natureza, que se dedicam à proteção da infância e da juventude devem formalizar e justificar as suas ações numa rede social mais ampla, a fim de legitimar o seu projeto e sua prática pedagógica e, de certa forma, ter o "aceite" prévio de um ente reconhecido organizador da política, no âmbito dos municípios. Os Conselhos Municipais da Criança e do Adolescente são um exemplo.

É evidente e inegável que as práticas socioeducativas possuem marcadores "institucionalmente" legitimados, tais como: legislações, metas, tempos, princípios, obrigatoriedade, entre outros, embora se diferenciem das práticas escolares no que diz respeito à inexistência de um currículo.

Da mesma forma é questionável a expressão "não formal" para nomear experiências cujo sentido de oposição pode definir, a priori, os sujeitos que Ihes são atinentes o que, em última instância, pode promover uma possível distinção entre os que acessam a educação e a cultura erudita e os que têm demandas por serviços sociais entendidos, no pior sentido da expressão, por seu viés assistencialista. Expressões como "menores", "sujeitos em situação 
de risco social e pessoal" demarcam essa dimensão e expressam a presença dos aludidos cultismos, nitidamente marcados como um modo "erudito" de referir-se a essas populações.

Além disso, é preciso considerar que as práticas de educação que ocorrem além da escola (em especial nos projetos socioeducativos e nos projetos que resultam de políticas públicas), ainda que contando com a presença de um mediador estagiário ou voluntário - o "educador" - em substituição à figura tradicional do professor, necessariamente visam implementar processos de ensino e aprendizagem. Isso implica reconhecer que, inevitavelmente, tanto quanto as práticas de educação escolar, as chamadas práticas de educação "não formal" também estão submetidas às modulações da dinâmica das relações poder-saber. Tal afirmação assume uma inflexão preocupante, na medida em que na inversa proporção do desaparecimento do intelectual engajado e/ou da liderança da comunidade, ocorre um engajamento artificial, expresso na figura do voluntário, determinando um nítido esvaziamento de sua dimensão crítico-política.

Por fim, o atributo formal das práticas de educação fora do contexto escolar, de modo crescente, evidencia-se em processos e procedimentos que contam com a presença de um corpo docente, metodologias definidas, mecanismos de avaliação interna e externa, entre outros, em ações que valorizam (muito) as regras, o ritual; totalmente adequadas para ocasiões solenes, protocolares que, por vezes, até Ihes visam conferir um caráter sério e oficial.

Desse modo, respaldadas por nossas reflexões e argumentos, defendemos a urgente necessidade da superação desse debate, por entendermos que se trata de um esforço estéril, além de constituir um importante limitador para a análise das inúmeras experiências de educação fora da escola e sua relação com o complexo contexto atual.

Por esses motivos, mesmo correndo o risco de permanecermos fixadas em uma lógica binária propomos denominar todas as práticas de educação que ocorrem no campo social - além ou aquém da escola - por meio da simples utilização do termo "educação não escolar" para distingui-las daquelas que ocorrem no interior da escola. Entendemos que a nomeação "escolar" e "não escolar" é mais adequada porque nos permite referenciar e demarcar a educação por aquilo que lhe é intrínseco: as práticas pedagógicas, eixo que baliza a utilização da expressão proposta. 


\section{AS DIFERENTES INTENCIONALIDADES DAS PRÁTICAS DE EDUCAÇÃO}

Historicamente, a realidade brasileira - caracterizada pela desigual distribuição de renda - produziu um contexto de marginalização e exclusão sociais cuja solução, necessariamente, passa pela instauração de uma nova ordem social que demanda tempo e investimentos. A fim de amenizar essa situação, tradicionalmente, inúmeras entidades e órgãos governamentais ou não, laicos ou confessionais, têm buscado implementar intervenções alternativas baseadas em práticas educativas. Em geral, trata-se de propostas engajadas, ao menos discursivamente, em projetos de transformação social que, geralmente, se desenvolvem no âmbito do que poderíamos chamar uma educação no e do campo social.

Assim, ao longo desse processo histórico - alicerçadas nas inúmeras experiências de educação popular latino-americanas, principalmente, ocorridas nos anos 1960, 1970 e 1980 - vimos surgir uma matriz teórico-prática que se tornou conhecida como "educação social". Contudo, Marlene Ribeiro questiona:

Se o processo de formação humana é de natureza social, como se poderia falar de uma educação social? Não seria esta qualificação do substantivo educação uma redundância ou mesmo uma redução da responsabilidade do social, tornado adjetivo pela educação substantivada? (2004, p. I)

Reiterando a riqueza da experiência da pedagogia do Movimento Sem Terra - MST - e, ao mesmo tempo, referenciando outras experiências de projetos populares, especialmente voltadas às populações mais vulneráveis, a referida autora adverte que a educação social é uma questão mais complexa do que aparenta.

Com efeito, na medida em que tais experiências estão voltadas para mudanças objetivas no campo social, suas propostas acabam sofrendo alterações ao longo do tempo, recebendo influências, por exemplo, dos movimentos ocorridos no Brasil, principalmente, após a década de 1970, que as conduziram a uma crescente aproximação com o Estado, quer como parceiro de uma atuação conjunta, quer como provedor de recursos para a execução de diversos projetos. 
Assim, ao longo das últimas décadas, pelo menos, uma mudança concreta pode ser observada: a gestão de projetos de educação não escolar, realizada por entidades do chamado terceiro setor e/ou por organizações não governamentais - ONGs -, tem configurado um novo cenário para as experiências de educação fora do âmbito escolar e demonstrado a crescente omissão do Estado de suas responsabilidades sociais. Outra mudança relevante pode ser observada na forma pela qual a maioria dessas práticas de educação fora da escola vêm perdendo muito de suas características de projeto popular de transformação social e de formação da consciência, com exceção apenas daquelas experiências que nasceram e ainda permanecem vinculadas aos movimentos sociais populares e a segmentos específicos da Igreja, que demarcam sua luta nas dimensões ético-políticas e educativas.

Evidentemente, esse processo de transformação tem suscitado diversas polêmicas e gerado inúmeras críticas, na medida em que, geralmente, constituem práticas protagonizadas pelo Estado e/ou executadas pelo terceiro setor e por ONGs, que, priorizando ações voltadas para grupos vulneráveis, tais como jovens, crianças, portadores de necessidades especiais, trabalhadores desempregados, entre outros, fundamentam-se em conceitos como "risco social", "vulnerabilidade social", "exclusão social" que, em geral, pouco ou nada contribuem para uma efetiva transformação das condições de existência desses sujeitos, apenas identificando quem são os novos sujeitos a serem temidos (Bauman, 1999).

No atual cenário de críticas e polêmicas em torno das práticas de educação não escolar, também assistimos a emergência de um vigoroso debate quanto às suas diferentes formas de nomeação. Temos observado que o critério adotado nesse debate para distinguir o "formal", o "não formal" e o "informal", ampara-se na tese da intencionalidade da ação educativa presente (ou não) nas três diferentes modalidades (Libâneo, 2005). Seguindo essa linha argumentativa, Gohn (2006, p. 29), afirma que "a questão da intencionalidade é um elemento importante de diferenciação" e demarca com precisão as diferenças entre estas modalidades, especialmente, entre a não formal e a informal. Assim, iniciando pela demarcação dos seus campos de desenvolvimento, segundo a autora:

....a educação formal é aquela desenvolvida nas escolas, com conteúdos previamente demarcados; a informal como aquela que os indivíduos aprendem durante 
seu processo de socialização - na família, bairro, clube, amigos etc., carregada de valores e culturas próprias, de pertencimento e sentimentos herdados: e a educação não-formal é aquela que se aprende "no mundo da vida", via os processos de compartilhamento de experiências, principalmente em espaços e ações coletivas cotidianas. (2006, p. 28)

Na medida em que nos dedicamos ao estudo sistemático dessas práticas e empreendemos um esforço para diferenciar estas modalidades educativas, tomando como eixo de análise, o exame do significado do termo formal, pareceu-nos pertinente a definição de três modalidades de educação (formal, não formal e informal), por intermédio da intencionalidade, bem como a tentativa de distingui-las por intermédio da demarcação dos seus campos de desenvolvimento.

Contudo, ao nos aproximarmos dessa discussão, percebemos que a perspectiva de análise que distingue seus campos de desenvolvimento realça a educação formal como sinônimo de educação escolar. Assim, entendendo que é preciso encarar os dilemas oriundos da combinação dos esforços para diferenciar essas modalidades educativas com o intento de definir os campos de desenvolvimento, buscamos tomar como eixo argumentativo de nossa análise a intencionalidade, visto ser esta apontada como importante "elemento de diferenciação" (Gohn, 2006).

Foi desse modo que encontramos motivos suficientes para argumentar que qualquer tentativa de identificar a presença ou a ausência de intencionalidade da ação educativa constitui um esforço improdutivo. Para nós, esta tese não se sustenta, simplesmente, porque a "intencionalidade" está presente em todas as práticas de educação, independentemente de esta ocorrer no interior do espaço escolar ou fora dele. Entendemos que as práticas de educação, sejam escolares ou não escolares, possuem uma intencionalidade e que mais produtivo seria debater como distinguir as diferenças entre as intenções que estão sempre presentes nos diferentes espaços educativos?

A educação desenvolvida nas escolas não é, também, um processo de socialização carregado de valores? Pensamos que sim. A diferença entre o que se ensina e aprende no interior da escola daquilo que se ensina e aprende nos processos de socialização próprios da família, de uma comunidade (ou bairro), do clube ou dos amigos é que os valores transmitidos e legitimados pela 
escola são os valores próprios da cultura hegemônica, que se autoproclama erudita, certa, neutra, padrão, em detrimento das culturas populares que são consideradas desviantes e, por este motivo, inferiores.

Acrescentamos que, na educação desenvolvida na escola, não existem os processos de compartilhamento de experiências, principalmente, em espaços e ações coletivas cotidianas. $\mathrm{Na}$ escola, a despeito da sua explícita intenção de ensinar apenas os valores próprios da cultura hegemônica (erudita), também circulam os valores de outras culturas de pertencimento, herdados pela tradição oral e, principalmente, sentimentos, emoções e paixões. Somente nessa perspectiva, tendemos a concordar que educação desenvolvida nas escolas ocorre fora do "mundo da vida".

Por isso, não é sem razão que vivemos em um tempo e em uma realidade em que a sociedade civil foi convocada a ser parceira do Estado na intervenção sobre o campo social. Na medida em que a educação escolar consolidou-se como uma prática "descolada da vida", assistimos ao crescimento vertiginoso de projetos sociais de caráter educativo, com características compensatórias. No entanto, na sua maioria, esses projetos referenciam uma educação voltada à cidadania, não mais no sentido da garantia da participação e organização da população civil - tal como ocorria nos anos 70 e 80 - mas no sentido de uma cidadania ressignificada para o exercício da civilidade, da responsabilidade e para a responsabilização social de todos (Gohn, 2002).

Numa proposição, nem sempre experimentada, de vivermos "melhor" na sociedade é que ações de cunho socioeducativo e projetos sociais, geralmente caracterizados por ações pontuais, de baixo custo e com recursos materiais, financeiros e humanos escassos, têm sido apresentados como direito dos que deles necessitam, conforme anuncia a Lei Orgânica da Assistência Social, de 1993.

Nesse panorama - talvez por inspiração na lógica cristã que propugna necessário fazer-se algo para ajudar os mais necessitados ou, simplesmente, para reafirmar ideias preconcebidas de que estes grupos sociais necessitam da intervenção de outrem - observamos o surgimento de personagens (o voluntário e/ou o estagiário) que são solicitados para lidar com o jovem em conflito com a lei, a mulher vítima da violência doméstica, o pequeno e precoce trabalhador, entre outros, por meio de ações que recaem mais sobre formas de controle e de assistencialismo do que de cuidado e fomento à cidadania plena. 
Em suma, entendemos que o complexo processo histórico brasileiro, produziu a emergência de inúmeras e diversificadas formas de intervenções educativas no campo social que, especialmente nas últimas duas décadas, na maioria, tem-se mostrado descontextualizadas e dissociadas dos pressupostos ético-políticos, configurando-se ações pontuais que apenas respaldam e legitimam a visão hegemônica de homem e de sociedade.

Pelo exposto, entendemos que mais do que distinguir modalidades de educação e apontar suas diferenças, seria importante confrontar estas práticas na sua materialização cotidiana, em que a despeito das formas de nomeação, poder-se-ia distinguir os projetos que estão sendo construídos e desenvolvidos com e pelas populações daqueles que estão sendo construídos e desenvolvidos para as populações.

Trata-se, portanto, de identificarmos as diferenças entre as intencionalidades, subsumidas nos diferentes projetos de educação no campo social, buscando identificar em cada um, a presença, ou não, de um compromisso ético-político manifesto tanto nas suas concepções quanto nos seus processos de construção, implementação e de gestão de práticas educativas.

\section{POR UMA CONCEPÇÃO AMPLIADA DE EDUCAÇÃO}

Trabalhamos com uma concepção ampliada de educação que considera a multidimensionalidade da condição humana e o dinamismo da vida no campo social, lócus em que ocorrem os processos de interação e onde estão presentes todas as práticas educativas, inclusive, as escolares.

Com esse modo de conceber a educação nos aproximamos de Humberto Maturana ( 1999), para quem a educação é um processo de interação que ocorre o tempo todo, confirmando o convívio em sociedade e ressaltando seus efeitos de longa duração, suas características conservadoras, além de sua característica de via de mão dupla, quem educa é, ao mesmo tempo, educado, bem ao gosto da pedagogia freireana, porque demarca sua amplitude para além da instituição escola e contextualiza o âmbito das práticas educativas sobre as quais nos referimos.

Para sustentar uma concepção ampliada de educação, também buscamos respaldo em Dorneles (apud Ferla, 2004) quando afirma que há uma ordem racionalizadora que se assenta na tríade composta por uma dimensão 
antropológica, uma dimensão metodológica e uma dimensão teleológica que transversaliza os diversos campos de práticas sociais, inclusive a produção de conhecimentos, para constituir um "modo verdadeiro" de ser e estar no mundo, universalizando um conjunto de valores capaz de produzir, na ordem ocidental moderna, as possibilidades consideradas legítimas de viver a vida. Essa ordem, derivada da cultura europeia que Ihe deu origem (seu norte), estabeleceu uma objetivação racionalizada para o ser/existir, instituindo a razão científica como forma de "iluminar" a compreensão do universo e constituir/ ordenar os modos de ser/existir e a ideia de progresso, traduzida no avanço ordenado em direção a maiores gradientes de estabilidade.

Foi a ordem racionalizadora moderna que conferiu centralidade à escola como lugar de formação destituindo outros espaços - antes privilegiados - de ensinar e aprender, dentre eles o convívio familiar e o comunitário. Além disso, muito recentemente, esta mesma ordem definiu a educação básica para todos, determinando a emergência e consolidação da escola pública também para os filhos dos trabalhadores empregados e desempregados.

Essas ponderações iniciais buscam situar a discussão a seguir: a educação não é uma prática exclusiva da escola, a educação também ocorre fora do espaço escolar e, nesse âmbito, possui objetivos e finalidades diversos e, portanto, exige reflexões que são complementares, porém de natureza distinta.

Vale lembrar que, historicamente, a educação sempre consistiu um espaço de contradições. Ao mesmo tempo em que se prestou a ratificar uma ordem estabelecida, também alimentou sonhos de mudança e, sob certas circunstâncias, até é capaz de transformar sujeitos e, consequentemente, a própria sociedade. A questão é que as contradições permeiam os sujeitos que estão envolvidos com esse pensar, ou seja, não existe um lugar "seguro", de onde podemos nos instalar e olhar o mundo com clareza, definindo a priori o ideal tanto de sujeitos que queremos construir como o de sociedade que almejamos.

Neste sentido, consideramos importante reconhecer que o acesso ao conhecimento e habilidades constitui parte do processo de formação humana, mas não deve ser confundido com sua totalidade. Questionamos a consensual concepção que atribui aos processos escolares os fins e os meios de toda a educação. Esta concepção articula a visão pragmática e utilitária predominante na ordem política e social ao papel atribuído à educação escolar de preparar os 
educandos para o exercício da cidadania. No entanto, esta concepção apenas confere o atributo de cidadão aos indivíduos que se apossam dos conhecimentos e habilidades considerados necessários para que se integrem como força de trabalho eficiente nos setores produtivos da economia capitalista.

Propositivamente, evidenciamos nossa compreensão de que a educação não se reduz apenas à aquisição de conhecimentos e habilidades necessários para a formação da força de trabalho, mas é resultado da ação humana e dos artefatos culturais que fazem parte da nossa herança civilizatória ocidental, hegemônica, Entendemos que a educação enseja as condições de reprodução da vida e de suas formas sociais, que devem estar orientadas pelo respeito às diferenças e pelos princípios da solidariedade e, por que não, da felicidade compartilhada. Entendemos que essas características constituem o fundamento da formação de um sujeito ético capaz de construir alternativas diante do imperativo de uma individualidade competitiva em que se baseia a sociedade capitalista.

Desta perspectiva, concebemos a educação para além dos espaços hegemônicos de disseminação dos conhecimentos instituídos pela racionalidade científica "iluminadora", questionando as instituições socialmente legitimadas, proprietárias do direito (e dever da) à transmissão desses conhecimentos.

Entendemos que na marginalidade dos conhecimentos instituídos, existe um universo plural de culturas, de linguagens, de expressões, de modos de existir e de ser que, ao atribuírem outros significados à própria existência, produzem outros saberes.

Consideramos que recuperar estes significados, ou construí-los, perceber os diferentes espaços nos quais estes significados são compartilhados constitui o mais importante sentido da educação. Desse modo, partilhamos com Streck (2006, p. 273) "a assertiva de que, apesar de todas as mudanças, permanece como fato ineludível que a educação é - também e sempre - um ato político".

\section{PRÁTICAS DE EDUCAÇÃO NÃO ESCOLAR: NUANÇAS E TENDÊNCIAS}

Antes de postularmos a construção de um corpo teórico transdisciplinar às práticas de educação não escolar, apresentaremos as diversas formas pelas quais elas se têm constituído, nas últimas décadas demonstrando suas nuanças e tendências. Nos anos recentes, principalmente em alguns países 
europeus, surgiu um campo de práticas diversas em diferentes espaços e, em geral, se procurou delimitar sua área de abrangência, definir agentes e usuários, o que parece apontar a emergência de mais uma especialização nas ciências humanas.

Ao nos aproximarmos de seus interlocutores - educadores sociais e/ ou pedagogos sociais - encontramos muito dissenso e algumas afinidades, especialmente em experiências desenvolvidas em Portugal, na Alemanha e na Espanha. Em comum, percebemos que sua origem remonta às práticas caritativas próprias do desenvolvimento inicial do capitalismo e a seus efeitos sobre os "não empregáveis". Apesar da ênfase na atuação socioeducativa, em geral, as práticas da chamada Educação Social na Europa recaem predominantemente sobre populações vulnerabilizadas - trabalhadores infantis, jovens em conflito com a lei, mulheres, idosos, presidiários, usuários de drogas, entre outros abordando as questões sociais de diferentes perspectivas, umas de caráter mais caritativo, outras com mais ênfase política, sindical, ou ainda outras de caráter mais educativo (Hamburguer, Lópes, 1998).

Embora sob distintas perspectivas, essas experiências produziram um acúmulo que resultou em um quadro teórico-metodológico detalhado e definiu uma especificidade - uma Pedagogia Social e/ou uma Educação Social - instituindo-a como profissão, com implícitos interesses de reserva de mercado, e demandando a formação de um "superprofissional" - o educador social e/ou pedagogo social - voltado para a educação para o consumo, a educação de adultos, a educação especial, a educação na terceira idade, a educação de sujeitos com "dificuldades de adaptação social" (estrangeiros imigrantes ilegais) etc.

Como se trata de uma profissão muito jovem, consolidada nas últimas décadas do século $X X$ e comprometida em dar respostas objetivas, ela se diferencia das práticas de trabalhadores sociais e assistentes sociais, segundo Marchena (2004), sendo que Carreras (1998, p. 257) ressalta seus "atrativos e promissores campos profissionais". Por sua vez, Caride (2005) destaca as condições de emergência da Pedagogia Social como ciência, disciplina e profissão.

Segundo os referidos autores, na Europa, a Educação Social precisa dar respostas educativas aos desafios sociais, econômicos e culturais enquanto o Trabalho Social - prática que resultou das políticas do Estado de Bem-Estar Social - orienta-se para ações assistenciais e de correção. Por sua vez, a prática 
do Serviço Social, no seu sentido estrito, dedica-se às necessidades individuais ou problemáticas coletivas, como as situações de pobreza, por exemplo, que demandam por assistência social com o propósito de melhorar o "bem-estar" e garantir o acesso ao direito da população atendida.

Diante de um quadro de profissões e regulamentações que delimitam especificidades muito próximas, Hamburguer e Lópes (1998) constatam que a linha que divide as diversas práticas sociais é muito tênue, advertindo que isso pode resultar em profissões cujos marcos teóricos e campos de intervenção são difíceis de definir. Em todo o caso, na Europa, o educador social parece ser o profissional devidamente titulado, ou em vias de titulação, que responde sobre ações de caráter socioeducativo, no âmbito de intervenções primárias, secundárias e terapêuticas. Os referidos autores também reforçam a tese de criação de postos de trabalho mediante uma Pedagogia Social, em um cenário em que as Faculdades de Pedagogia, para a carreira do magistério ou da formação de especialistas, se encontram, de certa forma, em recesso.

Carvalho e Santos (s/d., p. 14), ao destacarem a multidimensionalidade do educador social e da Educação Social, concluem por um educador que constitui um prático, especialista e militante, em que a pedagogia social se assume como "ciência e tecnologia do fenômeno e da intervenção socioeducativa ou pedagógico-social".

Da análise que realizamos sobre o panorama europeu, depreende-se que as experiências da chamada Pedagogia Social e/ou Educação Social (expressões que designam conceitos confusos que às vezes aparecem como sinônimos) e suas diferentes modalidades de formação (no âmbito do ensino superior e/ ou médio), configuram práticas de intervenção disciplinares, sustentando uma educação especializada, voltada para segmentos muito específicos, mesmo quando seu caráter generalista é ressaltado.

No que se refere ao contexto brasileiro das práticas de educação não escolar, percebemos a existência de movimentos distintos que delineiam um vasto campo de dispersão. Especialmente no âmbito das universidades brasileiras, por exemplo, identificamos a existência de linhas de pesquisas que abordam práticas de educação fora da escola, geralmente tratadas como educação não formal, em alguns programas de pós-graduação stricto sensu em educação. Também localizamos grupos de estudos que discutem o universo da infância e da juventude em situação de vulnerabilidade social, cultura das classes populares, 
movimentos sociais, entre outros, apontando para um possível diálogo entre a academia e outros espaços de práticas educativas. Além disso, localizamos disciplinas isoladas que fazem parte de grades curriculares de alguns cursos de formação de professores em nível de graduação e pós-graduação, assim como localizamos a existência de projetos de pesquisa que tomam as práticas de educação no campo social como objeto de estudo.

Desse modo, pudemos constatar que o afã europeu para instituir mais uma especialização nas ciências humanas, parece ainda não se ter instalado nas universidades brasileiras. Ao contrário, se buscarmos maior aproximação de estudos e debates sobre práticas de educação não escolar no âmbito das universidades, percebemos que o diálogo entre a academia e outros espaços de educação, ainda que contribua para uma reflexão sobre as especificidades dessas práticas e sobre seus pressupostos teóricos e metodologias, do ponto de vista quantitativo, ainda é pouco significativo.

No Brasil, a abordagem acadêmica sobre a temática da educação não escolar tem perseguido uma análise dos seus resultados, não raras vezes em detrimento de processos de avaliação que medem o impacto e efetividade social das ações, discutindo a presença e/ou ausência do Estado na oferta dessas práticas e problematizando a emergência do terceiro setor e as políticas afirmativas e o movimento social em torno delas. Além disso, ainda que de forma tênue, também se investiga o reflexo do caráter compensatório de tais ações para a autonomia dos sujeitos que são afetos às políticas sociais, especialmente, as de caráter assistencial.

Com relação a eventos que visam a debater especificamente a educação não escolar em nosso país, com exceção do que ocorre nas reuniões anuais da Associação Nacional de Pós-Graduação e Pesquisa em Educação' - Anped constatamos que estes ainda são episódicos. Em geral, as breves discussões sobre práticas socioeducativas são realizadas sob a forma de oficinas e de sessões de comunicações, em eventos que discutem a educação em geral.

Por força, talvez, da crescente oferta de propostas de intervenções socioeducativas, especialmente, no âmbito do terceiro setor e nos movimen-

I. Tradicionalmente, dois Grupos de Trabalho - GTs - acolhem experiências de educação social: - GT Educação Popular e o GT Movimentos Sociais, os quais têm acumulado trabalhos de referência na área. 
tos sociais, em junho de 200 I, longe dos espaços de discussão acadêmica, foi realizado no Anhembi, em São Paulo, um evento chamado $1^{\circ}$ Encontro Nacional de Educação Social². Somente em 2006, pela primeira vez no Brasil, ocorreu um evento de porte, promovido por uma universidade, voltado à discussão em torno das práticas educativas no campo social, designando-as como Pedagogia Social. Referimos-nos ao $1^{\circ}$ Encontro Internacional de Pedagogia Social, realizado pela Universidade de São Paulo - USP - com a publicação dos textos dos trabalhos apresentados, das conferências e das oficinas realizadas. A repercussão desse primeiro evento reforçou a realização do $2^{\circ}$ Congresso Internacional de Pedagogia Social, ocorrido no ano de 2008.

Roberto da Silva (2006), professor da USP e um dos realizadores do $1^{\circ}$ e $2^{\circ}$ congressos, justifica a emergência do debate em torno da educação não escolar considerando a abertura dada pela Lei de Diretrizes e Bases da Educação - LDB -, de 1996, ao substituir o currículo mínimo pelas diretrizes curriculares nacionais. Com efeito, a nova regulamentação das diretrizes do curso de Pedagogia, pelo Conselho Nacional de Educação - CNE (Parecer n. 5/2005), explicita esta possibilidade quando no art. 4º , parágrafo único, reconhece os contextos educativos não escolares como lócus de atividade docente.

Contudo, aparentemente, nem a abertura dada pela LDB/96 e nem a emergência do terceiro setor, a proliferação de ONGs e suas ações em prol de uma discussão mais vigorosa sobre a legislação em torno dos direitos sociais que alavancaram as práticas educativas no campo social, produziram alterações significativas nas grades curriculares dos cursos de formação acadêmica, no sentido de contemplar as especificidades do âmbito não escolar. Tampouco produziram efeitos que levassem a incorporação dessa temática nos debates sobre educação, apesar da tradição brasileira dos estudos de Paulo Freire e da educação popular.

Não obstante, no mesmo ano do $1^{\circ}$ Encontro Nacional de Educação Social, na 24a Reunião Anual da Anped, Maria da Gloria Gohn, já assinalava que a década de 90 fora um tempo de reformulações da educação popular. Referindo-se ao Congresso Internacional de Americanistas realizado em julho

2. Sobre este evento não conseguimos acessar à nenhum tipo de material que oferecesse informações sobre os conteúdos dos debates. 
de 1988, na Holanda, sobre educação popular na América Latina; ao evento de 1990, na Bolívia e, em 1995 em Santiago do Chile, faz um balanço das crises por que passaram as práticas educativas no campo social, nomeadas como "educação não formal":

Analisando-se os três encontros concluímos que nos anos 90 houve um redirecionamento dos objetivos da EP que alterou o sentido de suas ações. Antes os objetivos estavam centrados mais no contexto geral, na política, na estrutura da sociedade. Depois, os objetivos voltaram-se mais para os indivíduos em si, para sua cultura e representações. No novo paradigma, não há algo a ser criado, a partir da animação de um agente externo - o educador ou o facilitador - em termos de uma politização que desperte o educando para suas condições concretas de vida, em termos da pobreza e suas causas, de interesses de classe explorada e oprimida, de direitos sociais básicos que Ihes estão sendo negados pelas elites e outros. No novo paradigma, há algo a ser repassado de forma competente, com conteúdo, e que deve gerar uma reação nos indivíduos de forma que ele confronte o recebido com o que possui de sua experiência anterior e visão de mundo, e o reelabore. Isto significa que os indivíduos e os grupos têm de repensar e de reformular seus próprios conhecimentos e experiências. (200I, grifos nossos)

Para Gohn, nas últimas décadas, as transformações ocorridas no campo social inauguraram um novo paradigma, que parece apontar para um necessário movimento de profissionalização dos educadores sociais.

\section{ARTICULANDO SABERES PARA A INSTAURAÇÃO DE UM CORPO TEÓRICO TRANSDISCIPLINAR}

Ainda que reconheçamos os limites à formação em serviço para as práticas educativas no campo social, por que, geralmente, esse tipo de formação se tem apresentado como a única opção e por que esses espaços costumam ser pouco reflexivos, tornando-se por vezes rotineiros além de assoberbados por tarefas, tendemos a problematizar a proposta de uma profissionalização dos educadores sociais. 
Com base nesse entendimento, cabe às universidades reafirmarem o conceito de uma educação além da escola, mas consideramos desnecessário instituir um modelo de formação específico tal como tem ocorrido, especialmente, na Europa, sobretudo em algumas universidades portuguesas, alemãs e espanholas.

Nestas, as práticas de educação não escolar (geralmente nomeadas como Pedagogia Social e/ou Educação Social) apresentam-se como práticas especializadas que requerem formação específica capaz de habilitar um pedagogo social e/ou um educador social (no âmbito do ensino superior e/ou médio) para atuar em espaços escolares e/ou não escolares, porém voltados a determinados públicos. Essas experiências de educação e suas diferentes modalidades de formação constituem portanto, intervenções disciplinares, sustentadas em uma concepção de educação especializada.

Concordando com Marlene Ribeiro (2006), quando afirma que os termos pedagogia social e educação social remetem a sentidos diversos, consideramos desnecessária qualquer preocupação em delimitar e fixar contornos disciplinares que conduzam a uma formação/titulação acadêmica e, por isso, pensamos que insistir em estabelecer uma distinção entre ambas as nomeações é improdutivo e pouco relevante.

Em alguns momentos, ao reconhecer a importância de uma educação do e no campo social - aqui entendida como um corpo de conhecimento e um campo de intervenção peculiar - não compartilhamos da ideia de uma formação específica e especializada para o pedagogo. Isso por si só promoveria, novamente, a cisão do conceito de educação. Ao contrário, desejamos pautar nossa reflexão no sentido da valorização do caráter transdisciplinar que visualizamos nesse campo de conhecimento e de intervenção.

Mais do que delimitar contornos disciplinares, seria interessante explorar as potencialidades de uma educação do e no campo social para oferecer uma outra perspectiva de formação acadêmica. Reafirmamos a necessidade de uma revisão do próprio modelo de formação acadêmica de educadores; uma revisão que se abra para absorver elementos teórico-conceituais capazes de elucidar a complexidade dos processos e dinâmicas do campo social.

Entendemos que exercer práticas de educação no campo social implica buscar sustentação em teorias e conceitos oriundos de diversas áreas do 
conhecimento; buscar apoio na Filosofia, Sociologia, Economia, Psicologia, Antropologia, entre outras. Mais do que isso, exercer práticas de educação no campo social implica recuperar a educação popular como tendência pedagógica e metodológica, com o objetivo de promover as relações humanas a um grau de melhoria (Streck, 2006) e como um fio que costura as áreas de conhecimento entre si.

Se mantivermos uma visão limitada, por que parcial e fragmentada, dos processos e dinâmicas que habitam o campo social, manteremos também um tipo de análise incapaz de explorar o movimento e a fluidez dos processos educativos que ocorrem na marginalidade dos saberes instituídos, repetindo o mesmo equívoco da educação escolar que desconsidera e não toma como ponto de partida de sua ação a realidade própria de cada grupo, de cada sujeito.

Evidentemente, esta compreensão também implica uma concepção da realidade, em que o real não se encontra pré-definido mas resulta de uma elaboração social e coletiva que se faz e desfaz a todo instante, por que são os próprios sujeitos que definem a situação na qual se encontram e que, portanto, estão a construí-la e reconstruí-la. Isso implica também romper com a certeza de que partilhamos um mundo comum com pontos de vista idênticos sobre uma realidade incontestável.

Concebemos uma educação do campo social como uma ação educativa não escolar que pode e deve se abastecer dos conhecimentos provenientes de todas as disciplinas da área das Ciências Humanas e Sociais, articulando um corpo de saberes transversal capaz de instrumentalizar a prática de todos os profissionais que intervêm no campo social, inclusive os educadores (Moura, Zucchetti, 2007). Trata-se de uma educação que não constitui uma disciplina, mas uma "indisciplina" do pensamento de quem aceita os riscos de articular distintas formulações teóricas para fundamentar as práticas educativas que ocorrem no entremeio das relações sociais.

Por fim, a lógica binária utilizada para pensar e definir práticas de educação precisa ser superada e assim, quem sabe, dar-se-iam as condições para a emergência de um debate sobre os sujeitos da educação e as formas como são afetos às práticas educativas. Nessa perspectiva, a dimensão ético-política da educação deverá sobrepor-se aos debates atuais, entre eles, as formas de nomeação de práticas. 


\section{REFERÊNCIAS BIBLIOGRÁFICAS}

BAUMAN, Z. Globalização: as consequências humanas. Rio de Janeiro: Jorge Zahar, 1999.

BRASIL. Lei n. 8.742 de 7 de dezembro de 1993. Dispõe sobre a organização da assistência social e dá outras providências. Brasília: Imprensa Nacional, 1995.

. Lei n. 8.069 de 13 de julho de 1990. Estabelece o Estatuto da Criança e do Adolescente. Brasília: Imprensa Nacional, 1991.

CARIDE, J. A. Las Fronteras de la pedagogia social: perspectivas científica e histórica. BarceIona: Gedisa, 2005.

CARRERAS, J. S. Entrevista al profesor José María Quintana Cabanas. Pedagogía Social: Revista Interuniversitaria, Madrid, v. I2, n.4, p.257-261, 1998.

CARVALHO, A. D.; SANTOS, E. Novas racionalidades e novos imperativos da educação social. Porto: Faculdade de Letras da Universidade do Porto, s.d. Disponível em: <www. pedagogiasocial.cl/docs/copesoc/pdf>. Acesso em: 3 I ago.2005.

HOUAISS. A. Dicionário Houaiss da língua portuguesa. Disponível em: < http://houaiss.uol. com.br/busca.jhtm>. Acesso em: 27 set. 2008.

FERLA, A. A. Participação da população: do controle sobre os recursos a uma produção estética da clínica e da gestão em saúde. PHYSIS: Revista de Saúde Coletiva. Rio de Janeiro, v. 14, n. I, p. 85-108, 2004.

FREIRE, P. Que fazer: teoria e prática em educação popular. 2. ed. Petrópolis:Vozes, 1989.

GOHN, M.G. Educação não-formal e cultura política: impactos sobre o associativismo do terceiro setor. 2.ed. São Paulo, Cortez, 2005.

. Educação não-formal: participação da sociedade civil e estruturas colegiadas nas escolas. Ensaio: Avaliação, Políticas Públicas e Educação, Rio de Janeiro, v. I4, n. 50, p. 27-38, jan./mar. 2006.

. Educação popular na América Latina no novo milênio: impactos do novo paradigma. In: REUNIÃO ANUAL DA ANPED, 24, 200I, Caxambu. Anais... Caxambu: Anped, 2001. CD-ROM.

. Sociedade civil no Brasil: conceito e sujeitos atuantes. In: MAIA, M. (org.). Cadernos Ideação, Porto Alegre: Cempthom, 2002. p.73-82. (Políticas sociais para um novo mundo necessário e possível: palestras do Seminário Balanço e Perspectivas das Políticas Sociais no Cenário Mundial Atual, I; Forum Social Mundial, 2, 2002). 
HAMBURGUER, F; ; LÓPES, A. Reflexiones en torno a la situación de la pedagogía social en la universidad alemana. Pedagogía Social: Revista Interuniversitaria, Madrid, v. I2, n.4, p.233$241,1998$.

LIBÂNEO, J. C. Pedagogia e pedagogos, para quê? São Paulo, Cortez, 2005.

MARCHENA, J.A.M. (Org.). Educación social, trabajo social e servicios sociales. Sevilla: Universidad de Sevilla, Facultad de Ciencias de la Educación, Dpto. Teoría e Historia de la Educación/Pedagogía Social, 2004. (Resúmenes de los temas do curso acadêmico.) Disponível em: <www.us.es/pedsocial>. Acesso em: 30 ago. 2005.

MATURANA, H. Emoções e linguagens na educação e na política. Belo Horizonte: UGMG, 1999.

MOURA, E. P. G.; ZUCCHETTI, D. T. Educação não escolar: refletindo sobre práticas para uma (outra) epistemologia da pedagogia social. Contrapontos, Itajaí, v.7, n. I, p. I85-199, jan./abr. 2007.

NúÑEZ PÉREZ, V. Los Nuevos sentidos de la tarea de enseñar: más allá de la dicotomía "Enseñar vs asistir". Revista Ibero-Americana de Educación, n.33, set./dez. 2003. Disponível em: <http://www.rieoei.org/rie33a0l.htm>. Acesso em: 24 abr. 2006.

RIBEIRO, M. Exclusão e educação social: conceitos em superfície e fundo. Revista Educação e Sociedade, v.27, n.94, p. I55- 178, 2006. Disponível em: <ww.cedes.unicamp.br>. Acesso em: 8 ago. 2006.

. Uma educação social faz sentido? Alguns apontamentos. 2004. Disponível em: <http://www.ufrgs.br/tramse/argos/edu/2004/06/uma-educabrasil- I6-de-abril-de-2004. html>. Acesso em: 4 abr. 2006.

SILVA, R. Fundamentos teóricos e metodológicos da pedagogia social no Brasil. 2006. Disponível em: <http://www.proceedings.scielo.br/scielo.php?script=sciarttex\&pid=MS00000092006 $0001000 \mid$ 5\&lng=en\&nrm=iso $>$. Acesso em: 26 mar. 2007.

STRECK, R. D. A Educação popular e a (re)construção do público. Há fogo sob as brasas? Revista Brasileira de Educação, São Paulo, v. II , n. 32, p.272-284, 2006.

Recebido em: dezembro 2008

Aprovado para publicação em: novembro 2009 